Important Lessons from Studying the Chinese Economy

by

Gregory C. Chow, Princeton University

CEPS Working Paper No. 194

December 2009 


\title{
Important Lessons from Studying the Chinese Economy
}

\author{
Gregory C. Chow \\ Princeton University \\ December 7, 2009
}

In 1979 the United States and China established normal diplomatic relations, allowing me to visit China and study the Chinese economy. After doing so for thirty years since and advising the government of Taiwan in the 1960s and the 1970s and the government of the People's Republic of China in the 1980s and the 1990s this is an opportune moment for me to summarize the important lessons that I have learned. The lessons will be summarized in four parts: on economic science, on formulating economic policy and providing economic advice, on the special characteristics of the Chinese economy and on the experience of China's economic reform.

At the beginning I should comment on the quality of Chinese official data on which almost all quantitative studies referred to in this article were based. Chow (2006(a)) has presented the view that by and large the official data are useful and fairly accurate. The main justification is that every time I tested an economic hypothesis or estimated an economic relation using the official data the result confirmed the well-established economic theory. It would be a miracle if I had the power to make the Chinese official statisticians fabricate data to support my hypotheses. Even if I had had the power, most of the data had already been published for years before I conceived the ideas of the studies reported in this article.

\section{On economic science}

1.1 The basic theories of microeconomics, macroeconomics and financial economics apply to China. One should start with this proposition as a premise when studying the Chinese economy, but should be aware that there may be institutional differences that make it invalid. If by basic theory we mean not only the particular hypotheses presented in economics textbooks but the set of analytical tools in economics, the applicability is broader.

Examples of the applicability of the theory of consumer demand just drawn from my own studies include the estimation of total expenditure elasticities of demand for four categories of consumption goods in Chow (1985, chapter 5; 2007, chapter 9), studies of the demand for and supply of urban housing in China in Chow and Niu (2010), of demand for education in Chow (2006 (b)), and the demand and supply of healthcare in Chow (2009). All these studies confirm the basic theory, with estimated elasticities having the correct sign and a reasonable order of magnitude.

An example of applying the method of constrained maximization to explain behavior of state-owned enterprises in both the period of central economic planning and the period of the earlier years of economic reform is given in Chow (2007, chapter 15). The first model 
constructed for the planning period assumes an objective function of the enterprise to be a function of total output and leisure time of the manager. Leisure time is defined as total time minus the time devoted to management and the time devoted to negotiations to obtain the required inputs used in production. The second model constructed for the early years of economic reform assumes an objective function which has profits and leisure time of the management as arguments. The reason for changing the model for this period is that the institutions were changed. State enterprises were allowed to purchase inputs in the market, thus making the use of the manager's time to negotiate for inputs unnecessary. They were also able to maximize profit which is the difference between revenue and the cost of inputs. When economic theory is applied the models may be different from those used to explain Western market institutions but the basic tools of microeconomics, constrained maximization in this case, still applies.

The prices of stocks traded in the Shanghai Stock Exchange can be explained by the present value theory of stock prices, as reported in Chow (1999) and Chow (2007, chapter 14) where panel data regressions (in log-linear form) of stock prices of different firms in 1992-1998 were performed on their dividends and rates of growth of dividends and the regressions can explain the Chinese data well. The values of the estimated parameters, when compared with those obtained from data of the New York Stock Exchange and the Hong Kong Stock Exchange, were similar in magnitude and reflected institutional differences in a reasonable manner, as explained in Chow (2007, chapter 14).

Examples in macroeconomics include a study of inflation with the ratio of money supply to real output as the major determinant and formulated as an error correction model to describe the delayed effects is given in Chow (1987). The proposition of Milton Friedman on the effect of a monetary shock on output and prices, namely that the former effect is almost immediate but short-lived and that the latter effect is delayed but long lasting, is found to be valid in Chow and Shen (2006) using a VAR with log output, log price level and log money stock as the three variables. Both of these studies are summarized in Chow (2007, chapters 7).

A simple macroeconomic model for China consisting of a consumption function and an investment function was presented in Chow (1987) and later updated in Chow (2009(c)). The consumption function is based on the permanent income hypothesis of Hall (1978), implying that consumption is a random walk. The investment function follows the principle of accelerations, with investment dependent on the rate of change, rather than the level, of output and lagged investment. This model is found to explain Chinese annual data since 1952 well.

A study of economic growth in China since 1952 by the use of a Cobb-Douglas production function was first presented in Chow (1993) and later updated as described in Chow (2007, chapter 5). More on this study below.

1.2. Market economies of a variety of forms can all work. 
Laws of economics apply to market economies of a variety of institutional arrangements. The different institutions include the extent to which a Western-style legal system is in place as compared with the use of moral codes and a system of social network and personal connections to guide business conduct in China, known as guanxi.

For example the economically efficient town-ship and village enterprises flourishing in the 1980s and early 1990s behaved like private enterprises in a Western market economy as described in Chow (2007, chapter 16). Secondly, the financial crisis of the Asian economies as described in Chow (2007, chapter 4) can be explained by the same theories as for a financial crisis in a Western market economy. There is no need to appeal to "phony capitalism" to describe Asian market economies just because they are nonWestern.

\subsection{Economic development can occur under different forms of government.}

The Chinese economy has experienced rapid growth in a political environment different from those in Western democratic countries. Taiwan also experienced rapid economic growth from the 1960s to the 1980s under a government controlled by only one party. Before 1997 Hong Kong's market economy performed beautifully while being ruled by a government in London and not a democratic government of its own.

\subsection{Importance of human capital in economic development}

The quality of human capital, that is, the thinking, habit and skill of the population, is a major factor determining whether a developing country can develop rapidly. The other two major determining factors are the existence of a set of functioning (though possibly imperfect) market institutions and being in an early stage of development which allows the country to adopt the most advanced technology to catch up. My favorite evidence to support this point is the rapid economic growth of Germany and Japan after World War II when the physical capital of both countries were destroyed by the war but both countries had an abundance of high-quality human capital.

China happened to have an abundance of high-quality human capital in the form of skills of its workers and resourcefulness of its entrepreneurs and researchers, all having a habit of working hard. Such human capital was derived from China's cultural tradition in thousands of years. Different countries have different kinds of human capital. Some are more conducive to economic development than others. A part of the cultural tradition of China and other countries manifests itself in family education which may be more important than schooling in determining the human capital imbedded in a person and in a society. Different provinces in China have different potential for economic development just as different less developed countries, mostly because the qualities of human capital are different, which is related to geographical differences.

1.5. Possible to do economic forecasts because of validity of econometric models and parameter stability. 
Econometric models based on a sound economic theory are useful to provide accurate forecasts for the Chinese economy as well. One example is the forecasting of the overheating of the Chinese macro-economy in 2004 and inflation in later years due to monetary shocks resulting from an inflow of foreign exchange as China had a large trade surplus. I made such a forecast in a speech given in the Bank of China in Beijing in 2005. Other examples include the accurate forecast of China's inflation in 1985 when money supply increased by 50 percent in 1984 as described in Chow (1994, p. 94) and the forecast of China's economic growth given in Chow (2007, chapter 5).

\subsection{Also possible to forecast institutional changes using a similar methodology.}

This topic is discussed in Chow (2007, concluding chapter, sections 2 and 3). The methodology is qualitative but similar in nature and steps as used to perform econometric forecasts in capturing the most important factors and their interactions and in the use of judgment to determine whether these factors will continue to operate in the future. The three examples that I cited were the forecasting of economic reform to start after the disaster of the Cultural Revolution, why economic reform would succeed and why the Chinese economy would continue to grow for a long time. I predicted the continuation of rapid economic growth for China in publications through the late 1980s and the 1990s, including in particular in Chow (1989; 1994, chapter 6). I am making such a prediction now while writing this article. My simple working hypothesis underlying such a prediction is that the three fundamental engines for rapid growth, namely, high quality and abundance of human capital, a set of functioning market institutions and the early stage of development that allows China to catch up rapidly still prevail in China today, if we consider the less developed western provinces in China.

Another example is the prediction that Hong Kong would remain essentially the same after its return to China in 1997, or return to China in 1997 would not affect Hong Kong's way of life. I made this prediction in the late 1980s based on my understanding of the Chinese government through years of working relationship. I invested in Hong Kong stocks at the time when the Hang Seng Index was about 2000 and the Index went up to more than five times soon after the change in government because the behavior of the Chinese government in relation to Hong Kong was just as I had predicted. If this example is not convincing, let me suggest that this prediction is analogous to investing successfully in the stock of a company in a given industry based on knowledge of the quality of its management, which may be based on the predictor's personal relation or friendship with its Chairman and CEO. A more convincing example is that a professor can use his knowledge of a graduate student to predict how successful she will be as a scholar in the future. A more systematic method for prediction based on qualitative knowledge was pointed out in the last paragraph. Needless to say, predictions based on qualitative knowledge are subject to error as predictions based on quantitative knowledge by the use of econometric methods.

\section{On economic policy and economic advice}


This section draws from Chow (2008) discussing the steps or gaps between acquiring knowledge from economic research to learning how to give economic advice, up to the point of affecting changes in the society.

\subsection{A gap between academic knowledge and ability to apply it for solving practical problems}

First-class academic economists have failed to see what parts of economics to apply in making suitable policy recommendations. They recognize this point when they start serving as adviser in government positions, as many American academics do by taking leave of absence to work in the government. They can testify that they have learned to provide policy advice through experience. The inability of macroeconomists in general to give policy advice without practical experience is analogous to the inability of microeconomic theorists to serve as CEOs of major corporations.

Besides the understanding of economics, other qualifications are required to give policy advice. First is the ability to recognize which part of economic knowledge is relevant for application to the given practical economic problem at hand. A doctor who is trained in medical science may not always give the right treatment to a patient because he fails to recognize the nature of the patient's illness. It has been suggested that renowned economists at the International Monetary Fund failed to diagnose the problems for some economies including Indonesia in particular during the Asian Financial Crisis of 1997-9. When the problem was a lack of liquidity, the policy recommended was to introduce discipline to government spending, which was just opposite to what the situation required.

As an academic economist with a full professorship rank at Cornell (visiting), Harvard (visiting) and Columbia (adjunct) in the 1960s I did not know how to apply economic knowledge to solve economic problems until I began advising the government of Taiwan as a youngest member of a team led by the late T. C. Liu and S. C. Tsiang and appointed by President Chiang Kai-shek in 1967. I began to realize that when a practical economic problem appeared it was not easy to decide what economic tools should be applied. It was through practical experience in Taiwan that I first learned how to apply economic knowledge to solve real life problems.

2.2. A gap between choosing the right economic knowledge for application and making a sound policy recommendation

A good policy recommendation does not automatically follow the recognition of what economic theory is relevant to a practical problem at hand. The recognition is a necessary but not a sufficient. One example comes from my experience working in the State Commission for Reconstructing the Economic System, briefly called the Economic Reform Commission, of the People's Republic of China in the 1980s. The Commission was chaired by the Premier, Zhao Ziyang at the time, to show the importance of its work although the usual working meetings were chaired by Vice Chairman An Ziwen. A major issue was reform of the price system towards being market determined. Here we knew the problem was that certain prices were set too low as judged by the conditions of 
market demand and supply. The Economic Reform Commission was able to provide an excellent solution, the two-tier price system. In the case of residential housing, the existing tenants were given the right to stay in their apartments at low rents while commercial housing was allowed to be built and sold or rented at higher market prices. Those who could afford to pay for commercial housing was welcome to enjoy it. This solution to the housing problem was a Pareto improvement since no one was worse off and some people became better off in living in better and more expensive commercial housing. A second example was the pricing of raw materials supplied to state enterprises. Such materials were available at market prices for additional inputs needed beyond the amount supplied by government channels at below-market prices. A third example is the swap center in Shanghai where importers and exporters could trade foreign exchange at a market rate which was higher for US dollars than the official exchange rate but foreign exchange was made available when needed.

If a reader thinks that the above policy was based on such a simple idea that any practicing economist could have thought of it, he should recall the experience of the former Soviet Union and some Eastern European economies. These economies adopted a reform strategy of "shock treatment” by decontrolling prices overnight and by privatizing a large number of state enterprises within some five hundred days in the case of the former Soviet Union. This policy led to collapse in industrial production when stateowned enterprises were sold hastily to opportunistic investors who did not intend to manage them but purchased them at very low prices for resale. In adopting shock treatment as the policy for economic reform the governments of these countries were following the advice of some well-known American economists who understood the virtues of a market economy. This case illustrates that knowledge of economics does not guarantee having a good sense in providing advice on economy policy.

\subsection{Important points to note in giving economic advice}

First is the consideration of the feasibility of the policy. One should not give an advice which is politically or otherwise not feasible to achieve. Economists with their set ideals are often emotionally involved and cannot refrain from advocating them even when the ideal recommendations have no chance of being adopted. When they sell their impractical ideas to responsible government officials, they may even lose the latter's confidence, making it more difficult to give their advice later even when it is feasible.

Second is the choice of the right government officials to work with. This choice requires good judgment. If a potential adviser knows that important officials cannot understand or appreciate her viewpoint she should not attempt to advise them. To force good ideas on the wrong people would be counterproductive and would not lead to fruitful results. By a right government official I mean one who can understand the virtue of your recommendation and also has enough power to adopt a good proposal as government policy. I have met top government leaders who are not forceful enough to push good ideas through for adoption as government policy. Having the trust of such a leader is useless in affecting social change. 
Third is the choice of timing even if a potential advisor has found government officials intelligent enough to appreciate her ideas. If she tries to push her ideas at the wrong moment, she will not find receptive ears and obtain a favorable reception.

Fourth, an adviser needs to be open-minded and to recognize the possibility that she might be wrong. My own experience in working with members of the Economic Reform Commission in China has taught me important lessons about economics in action. I have learned as much for them as they might have learned from me. That is why interactive discussion to search for appropriate economic policies is a good strategy to follow.

In Taiwan in the 1970s there was a "Working Group of Five" that we worked with, consisting of the Governor of the Central Bank, the Minister of Economic Affairs, the Ministry of Finance, the Director General of Budget, Accounting and Statistics and the Secretary of the Executive Yuan (branch of government). They were the government officials responsible for formulating and carrying out major economic policies at the time. In many a summers, we sat around an oval shaped table, with these five sitting opposite to the five advisers from abroad. We met for one whole week in the mornings from nine to twelve. Each minister in turn would bring up his current economic problems for discussion while we listened, made comments and asked clarifying questions. After the first week, we went back to our offices to think, to discuss among ourselves and to do research on possible solutions to the problems presented to us. Six to eight weeks later the two groups met again. We presented our initial recommendations while they made comments and raised questions before a final draft of our recommendations was written up. The final draft was published in newspapers and became an important document having substantial impact on economic policy.

Serious discussions also took place with the same intensity in meetings with members of the Economic Reform Commission of the PRC. We met each time for about four to five consecutive days from nine to five. I invited selected members of the Taiwan team, in so far as possible, to participate as well. In the 1980s T. C. Liu had already passed away and S. C. Tsiang was still a top economic adviser to the government in Taiwan and it was not convenient for him to take part, but I succeeded in inviting him in March 1989 to meet with members of the Economic Reform Commission including An Ziwen, Vice Chairman of the Reform Commission, and Liu Hongru, Deputy Governor of China's Central Bank (and an enthusiastic reader of Milton Friedman's work) by arranging the meeting in Hong Kong.

The most pressing economic issue for China in March 1989 was the control of inflation. Our solution, the tried and proven solution of S. C. Tsiang to cure the inflation in Taiwan in the 1950s, was to raise the interest rate to ensure a positive real return to bank deposits. The Commission adopted our recommendation and we were confident that it would work and it did. In sum, the open minded discussions with economic officials in both Taiwan and China mainland have taught me a great deal about economics in practice and provided me with a broad perspective required to solve real life economic problems.

2.4. Using the framework of dynamic optimization to provide economic policy advice 
Section 1.5 has pointed out that econometric models are useful for forecasting in China. If so it should be useful in the formulation of good economic policies by setting the policy variables to achieve desirable targets for the variables of interest. The mathematical tool to achieve this, once an objective function of the variables of interest for a relevant time period in the future is given, is optimal control or dynamic optimization as presented in Chow $(1975,1997)$.

There was in the late 1970s a critique by Robert Lucas (1976) suggesting that the use of optimal control as a basis for economic policy advice was inappropriate because the parameters of the econometric model used would change as economic agents react to the policy or control rule of the government. Although many economists were persuaded by Lucas, others including Chris Sims (1980), Ray Fair (1984) and myself believed that his critique is invalid because the advice is not given in the form of a rigid rule that persists long enough for the economic agents to learn about and to react to. My explanation for the ready acceptance of the Lucas view by many economists is that by the middle 1970s econometricians in general had failed to build econometric models that were good enough to produce good forecasts. It was not difficult to build low-quality large-scale econometric models by extensive data mining, a practice which Ray Fair (1984) and Chow (1967) tried to avoid. Being disappointed by and having lost faith in the majority of econometric models, the profession ready accepted the Lucas critique, which also rode the waves of the adoption of the fashionable idea of "rational expectations."

Several considerations should be taken seriously in using the method of optimal control for economic policy recommendation. One should not simply and naively proceed to make policy recommendations in two steps: first, to find the optimal policy using econometric model and second, to sell the policy to policy makers. It may be better to use the government official's objective function than to use our own objective function if we are to help the government official in making a best decision from his point of view. However there is difficulty in achieving this because, not being technically equipped, a government official may not be able to communicate to us this objective function or be convinced that our recommendation will actually serve to achieve his objective.

A related point is that we need to acquire skill for explaining a result derived from the mathematics of dynamic optimization to a policy maker using a plain language and providing a good intuition. Furthermore, the economic adviser has to be able to instill confidence on the part of policy makers by successful communications on less technical matters. When the time comes to communicate the results of technical analysis as obtained by dynamic optimization, the government official may then be willing to be persuaded.

A better approach is to have available a collection of good policies rather than just a single optimum policy to recommend. The economist needs only to convince the government official to adopt just one of these policies. More importantly, after he has his set of good policies and is able to be persuasive, he should be open-minded enough to let the government officials influence him and teach him that there might be other policies 
than those in his collection. It was for both the economic adviser and the government officials to get together to work it out, as illustrated by my experience in working with government officials in Taiwan and in the PRC. Good policies can be and should be worked out cooperatively and interactively. In the case of economic advice to the Taiwan government, an econometric model originally built by T. C. Liu was used to forecast major economic variables for different macroeconomic policy options and the econometric work was frequently done in the office of the Director General of Budget, Accounting and Statistics.

\subsection{Implementation of government policies}

As discussed in Chow (2009 (a)) among the pressing problems arising from rural poverty in China today a most serious is the mistreatment of Chinese farmers by local Communist Party officials who have control over the affairs of local villages. Land contracted to farmers was illegally taken by local officials for urban development without adequate compensation. There is a law that guarantees the right of the farmers to keep the land that is contracted to them but this law has been violated many times, leading to fairly widespread but often unreported demonstrations and unrests by mistreated farmers. The central government could not uphold its policy to protect the farmers because it could not control the local party officials.

In the case of healthcare as discussed in Chow (2009 (b)), after the collapse of the Commune system that provided healthcare and other services, many rural residents now receive worse health care services than during the late 1970s. This is a major case of failure during the very successful economic reform process in China. In recent years, the central government has tried to institute a medical insurance system for all rural residents. The insurance costs 50 Yuan per person per year and the government is willing to pay 40 Yuan, equally divided between the central and the local government. However, many farmers still did not enroll in this insurance system as of the spring of 2007 mainly because they did not trust the government in actually paying for the insurance premium for their benefit or in delivering the services as promised to the insured.

Given the importance of implementation, I would suggest that before policy recommendations are made and perhaps even before research to support the policy is completed, problems of implementation should be taken into account. If one knows that a certain policy cannot be implemented, recommending it is useless. As I have suggested before, a policy has to be feasible for us to recommend it. A policy that has no chance of being successfully implemented should be treated as an infeasible policy.

It is equally important to consider the problem of policy implementation in the design of the policy itself. In Chow (2008 (b)) I suggested that if a provincial governor fails to enforce central environmental policies for protecting the environment, he should be subject to severe punishment, including the loss of his governorship. While making this recommendation I realized that the central government might not have such a strong resolve to adopt the policy that I recommend. However I considered this recommendation feasible as long as there is some chance for its adoption. 
2.6. Making Social Change without going through the government

The discussion in this section so far has concentrated on influencing the government in order to make social changes. There are two other important channels through which social changes can take place.

A most important channel is through the market. Social changes are made in a market economy by the actions of many individuals who innovate and by the adoption of their innovations through the market. Many universities and major corporations engage in research and development, the results of which are sold to the market and some have changed the society significantly.

A second important point known to economists is well expressed well by Keynes who pointed out that the world is influenced more by men of ideas than by politicians who often follow their ideas. Karl Marx had tremendous influence on many government officials for decades, whether his ideas were valid or not. My respected teacher Milton Friedman perhaps had more influence than any other economis during the second half of the $20^{\text {th }}$ century on the functioning of the American economy and many other economies than top government officials. His research has made a tremendous impact on society, including particularly in the formulation of monetary policy, the use of vouchers for paying tuitions, and the respect of freedom to choose in many aspects of life. He accomplished this by writing, speaking (on TV or in person) and teaching students.

\section{On the characteristics of China's economy}

I have discovered that the values of many parameters describing the Chinese economy can reveal its institution characteristics and that some of these parameters even remain constant before and after the economic reform initiated in 1978.

When Chinese farm families were free to build houses in the land distributed to them under the household responsibility system while the urban workers were provided subsidized housing in the early 1980s the total expenditure elasticity of demand for housing and fuel for farmers was high, equal to 1.78 as compared with the median of about 0.8 for the many countries studied by Houthakker (1957). See Chow (2007, pp. 166 and169). The total expenditure elasticity of demand for clothing in the fashionable Shanghai was as high as 1.61 while that of Beijing was 1.33 in the early 1930s. See Chow (2007, p. 170).

In a study by Johnson and Chow (1997), when the Mincer equation to explain log wage by log years of schooling, years of working experience, its square and dummy variables representing gender, minority ethnic group, and Communist Party membership using data for rural and urban population in China for the year 1987, the signs and magnitudes of all coefficients are correct and reasonable. The rate of returns to education for both urban and rural population were low, being 3.7 percent and 4.0 percent respectively. This result 
reflects the large fraction of the urban labor force working in state-owned enterprises and the income of farm families being only slightly affected by years of schooling in the period of study. Being female, being a member of a minority ethnic group (other than Han) and being a Communist Party member were found to have a significantly negative, negative and positive effect on wage respectively, except for Party membership for the rural sample which has a statistically insignificant effect.

It is quite amazing that the random walk hypothesis of Hall (1978) explains aggregate consumption and the accelerations principle explains aggregate investment in China during both the period of central planning and after economic reform. A macro model based on these two equations was found to fit Chinese annual data in the period 19521982 and also in the period 1979-2006. See Chow (2009 (c)). It is equally amazing that the same error-correction model with stable parameters can explain Chinese inflations before and after economic reform and likewise for the same VAR model that confirms Friedman's proposition on the effects of monetary shocks on aggregate output and the price level from 1952 to the 2000s. See Chow (2007, chapters 6 and 7).

In a study of China's economic growth using a Cobb-Douglas production function presented in Chow (1993) and updated in Chow (2007, chapter 5), the elasticity of output with respect to capital is found to be about 0.6 and with respect to labor to be about 0.4. These elasticity estimates agree with the estimate of 0.4 for the labor share of output for Chinese farm families given by Buck (1930) and with the estimate of 0.6 for output elasticity with respect to capital found in Mankiw, Romer and Weil (1992). These estimates remain unchanged before and after economic reform, but the increase in total factor productivity was found to be zero in the period 1952-1979 and to equal about 2.8 percent per year after 1979.

Chow (2002(a)) and Chow and Lin (2002) found that a similar study for the Taiwan economy yields an output elasticity with respect to labor of about 0.4 in the 1950s as shown by the fraction of output distributed to labor. This fraction increased gradually to about 0.48 in thirty years.

\section{On China's economic transformation process}

\subsection{Gradualism works}

In the discussion of economic reform in formerly planned economies, much debate centers on the issue whether the reform process should be gradual or rapid, the latter being referred to as shock therapy. I would not claim that gradualism works better for all countries including the Eastern European countries and the former Soviet Union since I have not studied these countries well enough to render an opinion. There is no doubt from my studies of the Chinese economy, however, that gradualism was the right policy and has worked for China's economic reform for the following reasons. 
First reform in China required receiving support from the Communist Party members to carry it out. It was impossible to tell the party members that a market economy is good after they had been told in no uncertain terms otherwise. It would take time and evidence to change their minds. Deng Xiaoping had the genius to advocate "seek truth from facts." This was to tell the Party members to respect evidence rather than ideology. An experiment was carried out in 1979 to give two thousand selected state enterprises more autonomy in decision making in the production of outputs. Foreign investment was first introduced in special economic zones, etc. All these took time.

Secondly the Party leadership did not have a blueprint for reform because they simply did not know what market institutions to adopt although they had learned that the existing planning system did not work through years of experience. They require time and experimentation to find the workable market institutions.

Third is the institutional inertia imbedded in entitlements provided to the state enterprises and the population. Urban population receiving housing subsidies in the form of very low rent of several yuan per month could not accept price reform that could raise the price by a substantial amount. Reform of prices had to proceed gradually.

More on these points is found in Chow (2007, chapters 3 and 4).

\subsection{Allowing both state sector and non-state sectors to co-exist and compete.}

A slow reform process means that many state run institutions would remain inefficient for a long time. To speed up economic growth, which is required to give reform momentum and support, the policy was to allow the non-state sectors to flourish and serve as an engine for growth. An example was the growth of the township and village enterprises. Even Deng did not expect the sudden appearance of these enterprises. Appropriate economic institutions would naturally appear and flourish, and they did in China, once opportunity was given.

\subsection{Use of Dual price system}

An institution supporting the coexistence of state and non-state enterprises is the dual price system as mentioned above. The state enterprises could obtain raw material from the state distribution channels at a below-market price as before but only for a fixed amount. In the mean time they could obtain the material in the market at a higher price. Since this fixed subsidy does not affect the optimum input and output decisions, the state enterprises could still behave optimally. The same dual price system applied to urban housing when higher priced housing was available in the market, and to the supply of foreign exchange when a foreign exchange swap center enabled the importers and exporters to trade foreign exchange at a market price.

\subsection{Economic liberation through the open-door policy}


Foreign trade and foreign investment, as well as travel abroad, were allowed, enabling the free flows of goods, capital, technology and people. This increased efficiency in the allocation of resources and helped speeding economic growth. China also improved its management skill and technology in the process, while the state enterprises became more efficient from competition of imports and of foreign owned enterprises. China has for years had an export surplus and accumulated a large amount of foreign reserves, over 2 trillion as of April 2009. It has begun investing overseas as it emerges as an outward looking economy. In terms of its total output measured in purchasing power parity terms China is already a great economic power, second only to the US.

However, China's economic liberalization process is gradual and cautious. In foreign trade, the exchange rate is not entirely market determined. Foreign investment has been subject to regulations. So are the banking and financial sectors. Derivative products in financial markets are introduced gradually. Consumers learn to use credit cards step by step. All these slow movements have protected China from much of the current financial crisis and economic slowdown in the rest of the world and enable China to play an important role in leading the world economy to recovery.

Studying the Chinese economy can help one become a better economist and may even be useful for improving the economic institutions of the world.

\section{References}

Buck, John L. 1930. Chinese Farm Economy. Chicago: The University of Chicago Press.

Chow, Gregory C. 1967, "Multiplier, accelerator and liquidity preference in the determination of national income in the United States," Review of Economics and Statistics. XLIV pp. 1-15.

1975, Analysis and Control of Dynamic Economic Systems. New York:

John Wiley.

1985 (a). The Chinese Economy. New York: Harper and Row.

1985 (b). "A model of Chinese national income determination,"

Journal of Political Economy, 93, 782-792

1987 "Money and price level determination in China," Journal of

Comparative Economics, 11, 319-333.

1989 ."Prospects of China's economic growth, foreign economic relations and cultural exchanges with the U.S.” Princeton Alumni Weekly, 27 September 1989, pp. 16-17. 
1991 "The Chinese Economy: Substantial Growth in the 1990's." presented at the Mid-Pacific Conference on The Evolving Pacific Basin: Problems and Opportunities for Trade and Investment. Commercial Times, Taiwan, March 27, 1991, p. 2.

1993 "Capital formation and economic growth in China," The Quarterly Journal of Economics, 108, 809-842.

1994 Understanding China's Economy. Singapore: World Scientific.

1997 (a) Dynamic Economics: Optimization by the Lagrange Method. New York: Oxford University Press.

1997 (b) “Challenges of China’s Economic System for Economic Theory,” American Economic Review, 87, 321-327.

1999 "Shanghai Stock Prices as Determined by the Present Value Model,” Journal of Comparative Economics, 553-561.

2002 (a) “Taiwan's Aggregate Production Function and Economic Growth," in Sheng-Cheng Hu and Chu-Tan Fu, ed. Essay on Economic Development in Memory of Academician Hsing Mo-huan, Taipei: Institute of Economics, Academia Siknica, pp. 21-43.

2002 (b) “Can economists forecast accurately?” a keynote address presented at the meeting of Academia Sinica in Taipei, July 1 2002. International Chinese Statistical Association Bulletin, July 2003, pp. 28-36.

Studies, June 2006.

2006 (a) “Are Chinese Official Statistics Reliable?” CESifo Economic

2006 (b) "Demand for Education in China," International Economic Journal, 20:2 (June 2006), pp. 129-147.

Chow, Gregory C. 2007. China's Economic Transformation. Blackwell Publishers, second edition.

2008 (a). "From research to social change," Comparative Studies (Bijiao, in Chinese). China Civic Press, issue 36, pp. 24- 33.

2008 (b) "China’s energy and environmental problems and policies," Asia-Pacific Journal of Accounting and Economics, 15, 55-70.

2009 (a) "Rural poverty in China: problem and Solution," in Ravi Kanbur and Xiaobo Zhang, ed. Governing Rapid Growth in China: Equity and Instituions. New York: Routledge, pp. 229-246. 
2009 (b) “An Economic Analysis of Health Care in China,” in Gordon G. Liu, Shufang Zhang and Zongyi Zhang, ed., Investing in Human Capital for Economic Development in China. Singapore: World Scientific.

2009 (c) "Note on a model of Chinese national income determination," Economic Letters, http://dx.doi.org/10.1016/j.econlet.2009.11.018.

and Anloh Lin. 2002, “Accounting for Economic Growth in Taiwan and Mainland China: A Comparative Analysis,” Journal of Comparative Economics, September, 507-530

and Linlin Niu. 2010. "Demand and Supply for Residential Housing in Urban China,” in Joyce Man, ed., China Housing Policy. Cambridge, MA: Lincoln Institute Press.

and Yan Shen. 2005. "Money, Price Level and Output in the Chinese Macro-Economy,” co-authored with Yan Shen, Asia-Pacific Journal of Accounting and Economics, 12, 91-111.

Fair, Ray C. 1984. Specification, Estimation and Testing of Macroeconomic Models. Cambridge, MA: Harvard University Press.

Hall, Robert. E. 1978. "Stochastic Implications of the Life Cycle-Permanent Income Hypothesis,” Journal of Political Economy, 86, 971-87.

Houthakker, H. S. 1957. "An international comparison of household expenditure patterns, commemorating the centenary of Engel’s law,” Econometrica, 25, 532-51.

Johnson, Emily N., and Gregory C. Chow. 1997. "Rates of Return to Schooling in China,” Pacific Economic Review, 2, 101-113.

Lucas, Robert. 1976. "Econometric Model Evaluation: A critique,” in K. Brunner and A. H. Meltzer, ed. The Philip Curve and Labor Markets. Amsterdam: North Holland Publishing Company.

Sims, Christopher A. 1980, “Macroeconomics and reality,” Econometrica, 48, 1-48. 